\title{
TRANSBUCCAL DELIVERY OF SPRAY DRIED LOVASTATIN FROM MUCOADHESIVE BUCCAL PATCHES AND IN VITRO CHARACTERIZATION
}

\author{
BHUVANESHWARI R. SHARANNAVAR*, ANAND P. GADAD
}

Department of Pharmaceutics, Kles College of Pharmacy Belagavi, Kle Academy of Higher Education and Research, Belagavi 590010, Karnataka, India

Email: bhuvi_rs@yahoo.co.in

Received: 22 Jun 2019, Revised and Accepted: 25 Jul 2019

\section{ABSTRACT}

Objective: The aim of the present work was to develop and characterize mucoadhesive film of spray dried Lovastatin (LVS) for buccal delivery to enhance bioavailability.

Methods: Mucoadhesive films were prepared by solvent casting technique by using different polymers HPMCK4M, HPMC E5LV and chitosan. The successful patches were evaluated for film thickness, weight, content uniformity, surface $\mathrm{pH}$, swelling index, folding endurance, ex-vivo residence time, ex-vivo bioadhesion test, in vitro drug release, ex-vivo drug permeation and stability study.

Results: The thickness of all prepared patches ranged from $0.21 \pm 0.07$ to $1.5 \pm 0.39 \mathrm{~mm}$, the weight of the film $89.10 \pm 0.6$ to $128.57 \pm 0.3 \mathrm{mg}$, drug content $85.47 \pm 0.87$ to $97.33 \pm 0.31 \%$, surface $\mathrm{pH} 5.6 \pm 0.67$ to $7.6 \pm 0.98$, swelling index $23.0 \pm 4.1$ to $76.5 \pm 3.6 \%$, folding endurance $165 \pm 1.9$ to $350 \pm 2.5$ respectively. Ex-vivo residence time ranged from $2.2 \pm 0.08$ to $8.2 \pm 0.17 \mathrm{~h}$ and ex-vivo bioadhesive strength $30 \pm 0.64$ to $66 \pm 0.43 \mathrm{~g}$. The formulations with HPMC E5 shown short period of residence time and shows weak force of adhesion., which might be because of low viscosity of the polymer which resulted into weak adhesion. The percentage drug release and ex-vivo drug permeation was in the following descending order HPMC $\mathrm{K} 4 \mathrm{M}>\mathrm{HPMC}$ E5LV>chitosan. These results confirm the extension of drug release in case of ionic polymer chitosan. The kinetics data shows that drug release and permeation follows nonfiction diffusion. Accelerated stability data revealed that there is no significant change in drug content, in vitro drug release and ex-vivo permeation.

Conclusion: It can be concluded that mucoadhesive buccal patch is a promising dosage form to enhance the drug bioavailability by preventing firstpass metabolism thus providing better therapeutic efficacy.

Keywords: Lovastatin, HPMCK4M, HPMC E5LV, Chitosan, Ex-vivo bioadhesion, Swelling index, Ex-vivo permeation

(C) 2019 The Authors. Published by Innovare Academic Sciences Pvt Ltd. This is an open-access article under the CC BY license (http://creativecommons.org/licenses/by/4.0/) DOI: http://dx.doi.org/10.22159/ijap.2019v11i5.34649

\section{INTRODUCTION}

The oral drug delivery is considered to be the most preferred route by majority of the patients amongst the various available routes of drug delivery. However, oral administration of drugs has certain disadvantages such as hepatic first-pass metabolism and enzymatic degradation within the GI tract that prohibits oral administration of various classes of drugs [1]. Since last three decades researchers have been focusing on buccal drug delivery, as it has shown ability to enhance the therapeutic efficacy of poorly effective oral drugs [2]. The direct entry of the drug into the systemic circulation avoids the first-pass hepatic metabolism leading to increase in bioavailability. Other advantages are low enzymatic activity, painless administration, easy drug withdrawal, facility to include permeation enhancers/enzyme inhibitors or $\mathrm{pH}$ modifiers in the formulation and versatility in designing as multidirectional or unidirectional release systems for local or systemic actions. Various mucoadhesive formulations were suggested for buccal delivery that includes buccal patches, adhesive tablets, and adhesive gels. However, buccal films are preferred over adhesive tablets in terms of flexibility and comfort [3]. Mucoadhesive formulations use polymers as adhesive components. These polymers form viscous liquids when hydrated, increasing their retention time over mucosal surfaces which may lead to interaction between polymers chain and the oral mucosa. Thus, the adequate selection of the polymer is crucial for the correct delivery of drugs in mucoadhesive formulations [4].

Lovastatin (LVS) is an antihyperlipidaemic drug. Its principal metabolite that is hydroxy acid is potent inhibitor of 3-hydroxy-3methylglutaryl coenzyme A (HMGCoA) reductase, which catalyses the conversion of hydroxy methyl gluterate to mevalonate which is an early and rate limiting step in biosynthesis of cholesterol [5]. It has been proven that LVS is effective as therapeutic and prophylactic agent in the management of major morbidities such as atherosclerosis, peripheral artirial disease and cardiovascular disease [6]. The drug lovastatin possesses some major limitations such as low solubility, less bioavailability (5\%), short half-life (1.1$1.7 \mathrm{~h}$ ), excretion in the bile (85\%), gastrointestinal side effects [7]. It is a white crystalline powder which has low aqueous solubility, which is $0.4 \mu \mathrm{g} / \mathrm{ml}$ at room temperature [8].

To overcome the low aqueous solubility of model drug LVS an attempt has been made to enhance the aqueous system solubility of LVS by preparing solid dispersion by spray drying technique by using PVPK30 polymer. The result findings are published in our previous paper "Physicochemical characterization and dissolution study of spray-dried amorphous Lovastatin with PVPK30"; The Pharma Innovation journal; 7(3)2018:498-502.

In the current study, the solid dispersions (prepared by spray drying technique SD4) showing best in-vitro drug release profile is selected and further developed into transbuccal patches, which helps to facilitate drug absorption through transbuccal route and overcome the other problems such as first-pass metabolism, excretion in the bile and other side effects. Hence by formulating spray-dried lovastatin into transbuccal films, an attempt has been made to improve the bioavailability of the drug LVS.

\section{MATERIALS AND METHODS}

\section{Materials}

LVS is obtained as gift sample by Biocon Limited, Bangalore Karnataka India. HPMCK4M by Yarrow chemical products Mumbai Maharashtra India and chitosan from Central Institute of fischeries technology Cochin, Kerala India. All other chemicals and solvents used in this study were of analytical grade reagents. 


\section{Methods}

\section{Compatibility studies}

Compatibility studies were carried out for SD4 and polymers used to prepare the transbuccal film. SD4, HPMC K4M, HPMC E5LV, chitosan polymers and transbuccal films were subjected for Infrared spectroscopic analysis.

Fourier transform infrared spectra of moisture-free powdered samples were obtained by using spectrophotometer (FT-IR Shimadzu Co., Japan) by potassium bromide (KBr) pellet method (2 $\mathrm{mg}$ of sample in $200 \mathrm{mg}$ of $\mathrm{KBr}$ ). The scanning range was $400-4000$ $\mathrm{cm}^{-1}$ and the resolution was $1 \mathrm{~cm}^{-1}$.

\section{Formulation of transbuccal films}

The solvent casting technique was used for the preparation of spray-dried LVS mucoadhesive buccal patches. The buccal patches were formulated by using different polymers i.e., HPMCK4M, HPMC E5LV and chitosan. These polymers were chosen from a series of trials on the base of the chemical compatibility, organoleptic properties and adhesiveness property. The placebo films were prepared. The processing variables used while formulating the placebo patches were the concentration of polymers and plasticizers. After results of placebo films were found to be satisfactory, the formulations containing different concentrations of polymers were prepared by using above-said polymers.

\section{Transbuccal film by using HPMC K4M}

The polymer HPMCK4M is dissolved in $10 \mathrm{ml}$ of mixture of ethanol and distilled water $(3: 2)$ and soaked for overnight. The polymeric solution was stirred on magnetic stirrer for $2 \mathrm{~h}$. The solid dispersion equivalent to $120 \mathrm{mg}$ LVS was added followed by addition of plasticizer $4 \%$ glycerol and $20 \mathrm{mg}$ of menthol as permeation enhancer. The mixture was stirred for $30 \mathrm{~min}$ and then poured into Petri dish, which is stored at $4{ }^{\circ} \mathrm{C}$ to remove air bubbles entrapped and finally dried at $37^{\circ} \mathrm{C}$ for $4 \mathrm{~h}$. The dried films were cut into $1 \mathrm{~cm}^{2}$ and packed in aluminum foil and stored $[1,4,9]$.

Table 1: Composition of the transbuccal film by using HPMC K4M

\begin{tabular}{|c|c|c|c|c|}
\hline Formulation code & Solid dispersion equivalent to LVS (mg) & HPMC K4M (mg) & $\begin{array}{l}\text { Plasticizer } \\
\text { Glycerol (\%) }\end{array}$ & $\begin{array}{l}\text { Permeation enhancer } \\
\text { menthol (mg) }\end{array}$ \\
\hline F1 & 120 & 100 & 5 & 20 \\
\hline $\mathrm{F} 2$ & 120 & 200 & 5 & 20 \\
\hline F3 & 120 & 300 & 5 & 20 \\
\hline $\mathrm{F} 4$ & 120 & 400 & 5 & 20 \\
\hline F5 & 120 & 500 & 5 & 20 \\
\hline F6 & 120 & 600 & 5 & 20 \\
\hline
\end{tabular}

\section{Transbuccal film by using HPMC E5}

The polymer HPMC E5 is dissolved in $10 \mathrm{ml}$ of a mixture of dichloromethane and ethanol (1:1) and soaked for overnight. The polymeric solution was stirred on magnetic stirrer for $2 \mathrm{~h}$. The solid dispersion equivalent to $120 \mathrm{mg}$ LVS was added followed by addition of plasticizer $0.7 \%$ glycerol and $20 \mathrm{mg}$ of menthol as permeation enhancer. The mixture was stirred for $30 \mathrm{~min}$ and then poured into Petri dish, which is stored at $4{ }^{\circ} \mathrm{C}$ to remove air bubbles entrapped and finally dried at $37{ }^{\circ} \mathrm{C}$ for $4 \mathrm{~h}$. The dried films were cut into $1 \mathrm{~cm}^{2}$ and packed in aluminum foil and stored $[4,10]$.

Table 2: Composition of transbuccal film by using HPMC E5

\begin{tabular}{lllll}
\hline Formulation code & \multicolumn{2}{l}{ Solid dispersion equivalent to LVS (mg) } & HPMC E5 (mg) & $\begin{array}{l}\text { Plasticizer } \\
\text { Glycerol (\%) }\end{array}$ \\
\hline F7 & & & 0.7 \\
F8 & 120 & 100 & 0.7 & 20 \\
F9 & 120 & 200 & 0.7 & 20 \\
F10 & 120 & 300 & 0.7 & 20 \\
F11 & 120 & 400 & 0.7 & 20 \\
F12 & 120 & 500 & 0.7 & 20 \\
\hline
\end{tabular}

\section{Transbuccal film by using chitosan}

Citric acid $20 \mathrm{mg}$ was dissolved in water. To this solution, chitosan polymer was added and soaked for overnight. The polymeric solution was stirred on magnetic stirrer for $2 \mathrm{~h}$. The solid dispersion equivalent to $120 \mathrm{mg}$ LVS was added. The mixture was stirred for 30 min and then poured into petridish, which is stored at $4{ }^{\circ} \mathrm{C}$ to remove air bubbles entrapped. The patches were finally dried at $25^{\circ} \mathrm{C}$ for $24 \mathrm{~h}$. The dried films were cut into $1 \mathrm{~cm}^{2}$ and packed in aluminium foil and stored [4].

Table 3: Composition of the transbuccal film by using chitosan

\begin{tabular}{lllll}
\hline Formulation code & Solid dispersion equivalent to LVS (mg) & Chitosan (mg) & $\begin{array}{l}\text { Plasticizer } \\
\text { Glycerol (\%) }\end{array}$ & Permeation enhancer citric acid (mg) \\
\hline F13 & & 100 & 3 & 20 \\
F14 & 120 & 200 & 3 & 20 \\
F15 & 120 & 300 & 3 & 20 \\
F16 & 120 & 400 & 3 & 20 \\
F17 & 120 & 500 & 3 & 20 \\
F18 & 120 & 600 & 3 & 20 \\
\hline
\end{tabular}




\section{Physicochemical characteristics of transbuccal patches}

\section{Film thickness and weight}

The thickness of all the formulations was measured by screw gauge (Mitutoyo Corporation, Kavasaki, Japan) and the weight of these films were determined by using electronic balance [1]

\section{Content uniformity}

The film was dissolved in $100 \mathrm{ml}$ isotonic phosphate buffer $\mathrm{pH}$ $6.8 \pm 0.2$, filtered $(0.22 \mu \mathrm{m})$, and resultant solutions were analyzed by UV Spectrophotometer at $238 \mathrm{~nm}$. The experiment was performed in triplicate [1].

\section{Surface pH}

The microenvironmental $\mathrm{pH}$ of all the formulations was measured so as to predict its effect on buccal mucosa. The formulations were first wetted by adding distilled water to its surface. The surface $\mathrm{pH}$ was then recorded by bringing a glass electrode near the surface of the formulation and allowing it to equilibrate for $1 \mathrm{~min}$. The average $\mathrm{pH} \pm \mathrm{SD}$ was determined for all formulations [1].

\section{Swelling index}

The buccal patches were weighed individually (designated as $\mathrm{W}_{1}$ ) and placed seperately in $2 \%$ agar gel plates, incubated at $37 \pm 1{ }^{\circ} \mathrm{C}$ and examined for any physical changes. At regular $1 \mathrm{~h}$ time intervals until $3 \mathrm{~h}$, films were removed from the gel plates and excess surface water was removed carefully using the filter-paper. The swollen films were then reweighed $\left(\mathrm{W}_{2}\right)$ and the swelling index (SI) was calculated using the following formula:

$$
\mathrm{SI}=\frac{\mathrm{W}_{2}-\mathrm{W}_{1}}{\mathrm{~W}_{1}} \times 100
$$

The experiment was performed in triplicate and average \pm SD values were recorded [1].

\section{Folding endurance}

Folding endurance of the films was determined by repeatedly folding and unfolding the films at the same place till it broke or for 300 times, which is considered to be a satisfactory value to reveal good folding-endurance properties. The number of times the film could be folded at the same place without breaking gave the value of the folding endurance [1].

\section{Ex-vivo residence time/adherence time}

The ex-vivo residence time is studied $(\mathrm{n}=3)$ to know the time required for complete erosion and/or detachment of the film from the mucosa surface. The fresh goat mucosa is fixed to the inner side of the beaker about $2.5 \mathrm{~cm}$ from the bottom. One side of the film was wetted with 1 drop of phosphate buffer $\mathrm{pH} 6.8$ and it is adhered to the surface of the buccal mucosa by applying slight force with fingertips for $30 \mathrm{~s}$. The beaker was filled with $500 \mathrm{ml}$ of phosphate buffer pH 6.8 and was kept at $37 \pm 0.5{ }^{\circ} \mathrm{C}$. After $2 \mathrm{~min}$, a $50 \mathrm{rpm}$ stirring rate is applied to simulate the buccal cavity environment and film adherence is monitored for $8 \mathrm{~h} \mathrm{[1]}$.

\section{Ex-vivo bioadhesion test}

Modified physical balance method is used to measure the ex-vivo mucoadhesive strength of prepared films. Fresh goat's buccal mucosa is taken and cut into piece and washed with phosphate buffer $\mathrm{pH} 6.8$ and tied to the open mouth of glass vial which is tightly fitted into a glass beaker which is filled with phosphate buffer $\mathrm{pH} 6.8$ in such way that, it just touched the buccal surface. The temperature of this beaker is maintained at $37^{\circ} \mathrm{C} \pm 1{ }^{\circ} \mathrm{C}$. The film is adhered to the lower side of a rubber stopper with cyanoacrylate adhesive. Two pans of the balance are balanced with $5 \mathrm{~g}$ weight on the right side of the pan, which is lowered the pan along with the film over the mucosa. The balance is kept in this position for $5 \mathrm{~min}$ of contact time. The water drops are added slowly to the right-hand side pan, until the film detached from the mucosal surface. The weight required to detach the film from the mucosal membrane surface is a measure of mucoadhesive strength. All the experiments are performed in triplicates and mean $\pm S D$ are reported. The following formula is used to calculate the detachment force [1].

Force of adhesion $(\mathrm{N})=(\mathrm{g} X$ 9.81 $) / 1000$

Detachment force $(\mathrm{N} / \mathrm{m} 2)=$ Force of adhesion $(\mathrm{N}) /$ Surface area (m2)

\section{In vitro drug release study}

In vitro drug release is carried out by paddle over disc dissolution apparatus. The transbuccal patch is placed beneath the disc in the dissolution jar containing $900 \mathrm{ml}$ phosphate buffer ( $\mathrm{pH}$ 6.8) solution. The bath temperature is maintained at $37 \pm 1{ }^{\circ} \mathrm{C}$ with $50 \mathrm{rpm}$ speed. Aliquots of $5 \mathrm{ml}$ are withdrawn at prespecified time intervals for $6 \mathrm{~h}$. same volume of fresh buffer solution is replaced. The withdrawn sample solution is filtered through $0.4 \mu \mathrm{m}$ membrane filter and the amount of drug is determined by measuring the absorbance of the aliquots at $238 \mathrm{~nm}$ using UV spectrophotometer and percentage drug release were plotted [1].

\section{Ex-vivo drug permeation study}

Franz diffusion cell is used to carry out ex-vivo drug permeation study. Fresh goat buccal mucosa is fixed on a diffusion cell between the donor and receptor compartment. The transbuccal patch is fixed on the mucosal membrane. Five $\mathrm{ml}$ of phosphate buffer $\mathrm{pH} 6.8$ in the donor compartment and $45 \mathrm{ml}$ of the phosphate buffer $\mathrm{pH} 6.8$ in the receptor compartment is filled as dissolution fluid. The fluids maintained at $37 \pm 1{ }^{\circ} \mathrm{C}$ and stirred continuously at speed of $50 \pm 5$ rpm. Aliquots of $1 \mathrm{ml}$ of the sample are withdrawn at prespecified time interval. Same volume of fresh buffer solution is replaced. The withdrawn sample solution is filtered through $0.4 \mu \mathrm{m}$ membrane filter and the amount of drug is determined by measuring the absorbance of the aliquots at $238 \mathrm{~nm}$ using UV spectrophotometer and percentage drug permeated were plotted [1].

\section{Stability study}

The accelerated stability of optimized formulation F3 is conducted as per ICH guidelines at $40{ }^{\circ} \mathrm{C} / 75 \% \mathrm{RH}$ up to 6 mo. Periodically samples are removed (initial, $1 \mathrm{mo}, 2 \mathrm{mo}, 3 \mathrm{mo}$ ) and analyzed for drug content, in vitro release and ex-vivo permeation [9].

\section{RESULTS AND DISCUSSION}

\section{Compatibility studies}

The IR Spectra of SD4 (SDSP) and transbuccal formulations (SDHPMCK4M, SD-HPMCE5LV and SD-chitosan) are shown in the fig. 1. Upon comparison of IR Spectra of SD4(SDSP) and transbuccal formulations(SD-HPMCK4M, SD-HPMCE5LV and SD-chitosan), it was found that the characteristic peaks of LVS in SD4 were $3535 \mathrm{~cm}$ ${ }^{1}$ (alcohol OH stretch), $3016 \mathrm{~cm}^{-1}$ (olefinic $\mathrm{CH}$ stretching vibrations) $1725 \mathrm{~cm}^{-1}$ and $1695 \mathrm{~cm}^{-1}$ (lactone and ester carbonyl stretch) also found in transbuccal formulations along with characteristic peaks of respective polymers. It can be concluded by these observations that there are no possible interactions between the SD4 and polymers.

\section{Formulation of transbuccal films}

The formulations containing different concentrations of polymers were prepared and their effects on physicochemical characteristics were studied. However, the selections of plasticizer were finalized during placebo film preperation.

\section{Physicochemical charecteristics of transbuccal patches}

The physicochemical charecteristics data of transbuccal patches are shown in the tables (4-6) below. 



Fig. 1: FTIR spectra of SD4 (SDSP) and transbuccal formulations (SD-HPMCK4M, SD-HPMCE5LV and SD-Chitosan)

Table 4: Physicochemical characteristics of transbuccal film by using HPMC K4M (F1-F6)

\begin{tabular}{lllllc}
\hline Formulation code & $\begin{array}{l}\text { Thickness } \\
(\mathbf{m m})^{*}\end{array}$ & $\begin{array}{l}\text { Weight of film } \\
\text { (mg) }\end{array}$ & Drug content (\%) & Surface pH $^{*}$ & Swelling index (\%) $^{*}$ \\
\hline F1 & $0.27 \pm 0.05$ & $91.91 \pm 0.2$ & $91.71 \pm 0.33$ & $6.2 \pm 0.07$ & $31.7 \pm 3.5$ \\
F2 & $0.34 \pm 0.02$ & $101.25 \pm 0.3$ & $93.23 \pm 0.41$ & $6.4 \pm 0.05$ & $42.9 \pm 5.1$ \\
F3 & $0.51 \pm 0.04$ & $108.32 \pm 0.4$ & $95.75 \pm 0.56$ & $6.7 \pm 0.04$ & $56.0 \pm 2.1$ \\
F4 & $0.62 \pm 0.01$ & $115.56 \pm 0.2$ & $94.80 \pm 0.61$ & $6.4 \pm 0.12$ & $57.9 \pm 2.8$ \\
F5 & $0.68 \pm 0.03$ & $125.46 \pm 0.6$ & $91.68 \pm 0.23$ & $6.3 \pm 1.23$ & $49.4 \pm 1.8$ \\
F6 & $0.81 \pm 0.1$ & $132.03 \pm 0.8$ & $89.34 \pm 0.17$ & $5.8 \pm 0.98$ & $61.3 \pm 1.6$ \\
\hline
\end{tabular}

*Data are expressed as mean \pm standard deviation of the mean [SD], $\mathrm{n}=3$.

Table 5: Physicochemical characteristics of transbuccal film by using HPMC E5 (F7-F12)

\begin{tabular}{|c|c|c|c|c|c|c|}
\hline Formulation code & $\begin{array}{l}\text { Thickness } \\
(\mathrm{mm})^{*}\end{array}$ & $\begin{array}{l}\text { Weight of film } \\
\text { (mg) }^{*}\end{array}$ & Drug Content (\%) & Surface $\mathbf{p H}^{*}$ & Swelling Index (\%)* & Folding endurance ${ }^{*}$ \\
\hline F7 & $0.21 \pm 0.07$ & $89.10 \pm 0.6$ & $90.23 \pm 0.51$ & $7.6 \pm 0.98$ & $23.0 \pm 4.1$ & $326 \pm 4.7$ \\
\hline F8 & $0.27 \pm 0.04$ & $98.91 \pm 0.5$ & $95.27 \pm 0.47$ & $6.7 \pm 0.07$ & $27.0 \pm 3.6$ & $319 \pm 5.1$ \\
\hline F9 & $0.55 \pm 0.03$ & $103.25 \pm 0.3$ & $97.33 \pm 0.31$ & $6.9 \pm 0.12$ & $48.2 \pm 1.1$ & $345 \pm 1.8$ \\
\hline F10 & $0.82 \pm 0.02$ & $112.16 \pm 0.2$ & $93.82 \pm 0.11$ & $6.3 \pm 0.83$ & $52.0 \pm 2.6$ & $337 \pm 3.1$ \\
\hline F11 & $0.88 \pm 0.06$ & $121.36 \pm 0.5$ & $88.67 \pm 0.61$ & $7.2 \pm 1.23$ & $61.3 \pm 2.3$ & $312 \pm 2.5$ \\
\hline F12 & $0.91 \pm 0.1$ & $128.57 \pm 0.3$ & $85.47 \pm 0.87$ & $6.4 \pm 0.03$ & $56.4 \pm 5.2$ & $336 \pm 4.5$ \\
\hline
\end{tabular}

${ }^{*}$ Data are expressed as mean \pm standard deviation of the mean [SD], $\mathrm{n}=3$.

Table 6: Physicochemical characteristics of transbuccal film by using chitosan (F13-F18)

\begin{tabular}{|c|c|c|c|c|c|c|}
\hline Formulation code & $\begin{array}{l}\text { Thickness } \\
\text { (mm)* }\end{array}$ & $\begin{array}{l}\text { Weight of film } \\
\text { (mg)* }\end{array}$ & Drug content $(\%)^{*}$ & Surface pH $^{*}$ & Swelling index $(\%)^{*}$ & Folding endurance $^{*}$ \\
\hline F13 & $0.92 \pm 0.03$ & $91.91 \pm 0.4$ & $93.51 \pm 0.43$ & $5.6 \pm 0.67$ & $54.4 \pm 5.2$ & $193 \pm 1.1$ \\
\hline F14 & $0.98 \pm 0.06$ & $104.25 \pm 0.5$ & $94.23 \pm 0.71$ & $6.2 \pm 0.12$ & $58.2 \pm 1.7$ & $194 \pm 2.5$ \\
\hline F15 & $1.15 \pm 0.07$ & $103.32 \pm 0.2$ & $93.75 \pm 0.76$ & $6.5 \pm 0.27$ & $63.3 \pm 1.6$ & $199 \pm 3.7$ \\
\hline F16 & $1.12 \pm 0.53$ & $108.56 \pm 0.1$ & $95.80 \pm 0.41$ & $6.7 \pm 1.63$ & $68.3 \pm 1.6$ & $208 \pm 0.8$ \\
\hline F17 & $1.5 \pm 0.39$ & $122.46 \pm 0.7$ & $92.68 \pm 0.73$ & $7.2 \pm 0.28$ & $76.5 \pm 3.6$ & $176 \pm 3.8$ \\
\hline F18 & $1.4 \pm 0.81$ & $128.03 \pm 0.4$ & $91.62 \pm 0.82$ & $6.5 \pm 0.83$ & $73.3 \pm 6.1$ & $165 \pm 1.9$ \\
\hline
\end{tabular}

${ }^{*}$ Data are expressed as mean \pm standard deviation of the mean $[\mathrm{SD}], \mathrm{n}=3$.

As the concentration of polymers increases, both film thickness and weight of the patches also increases. Weight of the film ranged from $89.10 \pm 0.6$ to $132.03 \pm 0.8 \mathrm{mg}$. Weight and thickness are directly related to the accuracy of the dose distribution in the film. The thickness of the film ranged from $0.21 \pm 0.07$ to $132.03 \pm 0.8 \mathrm{~mm}$. the films of chitosan shown highest thickness. Drug content ranges from 
$85.47 \pm 0.87$ to $97.33 \pm 0.31$. Uniformity in drug content is important parameter in formulation which confirm reproducibility of the product. The assay of drug content at three different places in each film showed that the drug was uniformly distributed throughout the films. The surface $\mathrm{pH}$ ranged from 5.6 to 7.6 which ensure there is no mucosal irritation due to the formulation.

The swelling index study was carried out to find out the degree of swelling of buccal films in simulated saliva solutions. HPMCK4M and HPMC E5 films started swelling after 5 min and chitosan after 30 min when hydrated on agar medium due to the swellable hydrophillic polymers. The results shown that as the polymer concentration increases the swelling index was also increased. As per the study carried out by the authors Pankaj kumar et al., [1] swelling of the polymers makes strong secondary hydrogen bonding with buccal mucosa and thus results in good mucoadhesion which provides unidirectional release of the drug. Chitosan buccal films (F13 to F 18) shown high values of swelling index as compared to HPMC films (F1 to F12). H. Castan et al., [2] stated that this may be due to chitosan when wetted can gain weight and size by $150 \%$. This high value of swelling index causes discomforts to the patient.

All the developed formulations were flexible and shown good folding endurance. However, HPMC K4M and HPMC E5 formulations (F1 to
F12) shown good folding endurance but in case of chitosan containing formulations (F13 to F18), the films became brittle, lost elasticity as the polymer concentration increased. Hence the folding endurance values decreased as the polymer concentration increased.

\section{Ex-vivo residence time}

Residence of film is directly related to the mucoadhesive strength, which is consequence of interaction between mucin and polymers. Further adequate hydration is required for the polymers to get charged and impart sufficient mucoresidence. Ex-vivo residence time ranged from $2.2 \pm 0.08$ to $8.2 \pm 0.17 \mathrm{~h}$. In the formulations with HPMC K4M polymers (table 7) containing films, the presence of hydroxyl groups which facilitate uptake of water into polymer matrix and enhance mucoadhesiveness. These polymers also form viscous liquids when hydrated with increasing their retention time over mucosal surfaces, which may lead to adhesive interactions. The formulations with HPMC E5 (table 8) shown short period of residence time, which might be because of low viscosity of the polymer which resulted into weak adhesion. In case of formulations with chitosan (table 9), there is interaction between positively charged amino group and negatively charged mucin of membrane and helps in bioadhesion for longer duration of time.

Table 7: Physicochemical characterization, cumulative percentage release and percentage drug permeated of F1-F6

\begin{tabular}{|c|c|c|c|c|c|}
\hline $\begin{array}{l}\text { Formulation } \\
\text { code }\end{array}$ & $\begin{array}{l}\text { Ex-vivo residence } \\
\text { time* }^{*}\end{array}$ & $\begin{array}{l}\text { Ex-vivo bioadhesive } \\
\text { strength }(\mathrm{g})^{*}\end{array}$ & $\begin{array}{l}\text { Detachment force } \\
(\mathrm{N} / \mathrm{m} 2)\end{array}$ & $\begin{array}{l}\text { \% Drug released } \\
\text { after } 6 \mathrm{~h}^{*}\end{array}$ & $\begin{array}{l}\% \text { Drug permeated } \\
\text { after } 6 h^{*}\end{array}$ \\
\hline F1 & $6.1 \pm 0.12$ & $40 \pm 1.41$ & 3920 & $97.78 \pm 1.08$ & $96.78 \pm 1.1$ \\
\hline $\mathrm{F} 2$ & $6.2 \pm 0.08$ & $42 \pm 0.86$ & 4116 & $95.32 \pm 3.5$ & $94.24 \pm 1.0$ \\
\hline F3 & $6.5 \pm 0.10$ & $43 \pm 1.07$ & 4214 & $94.17 \pm 0.62$ & $93.27 \pm 2.6$ \\
\hline F4 & $7.2 \pm 0.15$ & $44 \pm 1.43$ & 4312 & $92.34 \pm 1.4$ & $87.34 \pm 4.4$ \\
\hline F5 & $7.3 \pm 0.11$ & $45 \pm 1.86$ & 4410 & $89.24 \pm 2.0$ & $77.43 \pm 3.0$ \\
\hline F6 & $7.4 \pm 0.13$ & $47 \pm 0.88$ & 4606 & $86.17 \pm 1.2$ & $68.42 \pm 1.3$ \\
\hline
\end{tabular}

*Data are expressed as mean \pm standard deviation of the mean $[\mathrm{SD}], \mathrm{n}=3$.

Table 8: Physicochemical characterization, cumulative percentage release and percentage drug permeated of F7-F12

\begin{tabular}{|c|c|c|c|c|c|}
\hline $\begin{array}{l}\text { Formulation } \\
\text { code }\end{array}$ & $\begin{array}{l}\text { Ex-vivo residence } \\
\text { time* }^{*}\end{array}$ & $\begin{array}{l}\text { Ex-vivo bioadhesive } \\
\text { strength (g) }\end{array}$ & $\begin{array}{l}\text { Detachment force } \\
(\mathrm{N} / \mathrm{m} 2)\end{array}$ & $\begin{array}{l}\text { \% Drug released } \\
\text { after } 6 \mathrm{~h}^{*}\end{array}$ & $\begin{array}{l}\% \text { Drug permeated } \\
\text { after } 6 \mathrm{~h}^{*}\end{array}$ \\
\hline F7 & $2.2 \pm 0.08$ & $30 \pm 0.64$ & 2940 & $94.5 \pm 1.4$ & $90.45 \pm 3.2$ \\
\hline F8 & $2.3 \pm 0.13$ & $31 \pm 0.76$ & 3038 & $92.7 \pm 1.1$ & $89.57 \pm 3.9$ \\
\hline F9 & $2.6 \pm 0.18$ & $32 \pm 0.63$ & 3136 & $91.32 \pm 1.2$ & $86.45 \pm 3.0$ \\
\hline F10 & $2.7 \pm 0.16$ & $34 \pm 0.35$ & 3332 & $90.88 \pm 1.7$ & $81.37 \pm 0.8$ \\
\hline F11 & $2.7 \pm 0.16$ & $36 \pm 0.41$ & 3528 & $89.88 \pm 1.7$ & $78.73 \pm 1.3$ \\
\hline F12 & $2.8 \pm 0.17$ & $37 \pm 0.36$ & 3626 & $86.47 \pm 3.1$ & $71.56 \pm 0.5$ \\
\hline
\end{tabular}

*Data are expressed as mean \pm standard deviation of the mean $[\mathrm{SD}], \mathrm{n}=3$.

Table 9: Physicochemical characterization, cumulative percentage release and percentage drug permeated of F13-F18

\begin{tabular}{|c|c|c|c|c|c|}
\hline $\begin{array}{l}\text { Formulation } \\
\text { code }\end{array}$ & $\begin{array}{l}\text { Ex-vivo residence } \\
\text { time* }\end{array}$ & $\begin{array}{l}\text { Ex-vivo bioadhesive } \\
\text { strength }(\mathrm{g})^{*}\end{array}$ & $\begin{array}{l}\text { Detachment force } \\
(\mathrm{N} / \mathrm{m} 2)\end{array}$ & $\begin{array}{l}\text { \% Drug released after } \\
6 \mathrm{~h}^{*}\end{array}$ & $\begin{array}{l}\% \text { Drug permeated } \\
\text { after } 6 \mathrm{~h}^{*}\end{array}$ \\
\hline F13 & $7.2 \pm 0.17$ & $54 \pm 0.52$ & 5292 & $76.44 \pm 3.1$ & $73.25 \pm 1.7$ \\
\hline F14 & $7.5 \pm 0.08$ & $57 \pm 0.84$ & 5586 & $74.15 \pm 1.0$ & $69.83 \pm 4.8$ \\
\hline F15 & $7.9 \pm 0.12$ & $60 \pm 0.57$ & 5880 & $72.35 \pm 2.2$ & $65.23 \pm 2.8$ \\
\hline F16 & $8.1 \pm 0.61$ & $62 \pm 0.33$ & 6076 & $71.83 \pm 3.6$ & $63.12 \pm 3.6$ \\
\hline F17 & $8.1 \pm 0.91$ & $65 \pm 0.57$ & 6370 & $70.79 \pm 2.5$ & $60.56 \pm 2.6$ \\
\hline F18 & $8.2 \pm 0.17$ & $66 \pm 0.43$ & 6468 & $68.73 \pm 1.1$ & $57.34 \pm 2.1$ \\
\hline
\end{tabular}

* Data are expressed as mean \pm standard deviation of the mean $[\mathrm{SD}], \mathrm{n}=3$.

\section{Ex-vivo bioadhesion test}

Mucoadhesive strength plays an important role in proper adherence of the film to the mucosal surface. Excessive adhesion may cause discomfort to the patient leading to the patient in compliance. Hence optimum mucoadhesion is required for film for effective therapy.

The Ex-vivo bioadhesive strength and Detachment force value are shown in the above table (7-9). Transbuccal films with HPMC K4M (F1-F6); shows good mucoadhesion, which may be attributed to the hydration and liquid entrapment in the polymer network, after formation of viscous polymeric network, however HPMC E5 (F7F12) polymer films shows the weak force of adhesion. According to Magdy et al., [12] this might be because of its low viscosity of the polymer. Apart from this, hydrophilicity PVP K30 (from Solid dispersions which is incorporated in the transbuccal film) might further have weakened the force of adhesion. The transbuccal films of chitosan (F13-F18) also show good mucoadhesion. According to Cui et al. [13] the strong viscoelastic property and structure of 
chitosan might be attributed to its high mucoadhesive force which occurs because of interaction between amino group of chitosan and mucin of biomembrane.

\section{In vitro drug release}

The drug release study was carried out over a period of no longer than $6 \mathrm{~h}$ given that formulations cannot remain for longer period $\mathrm{s}$ on the surface of the buccal membrane.

The drug release profile of formulations is shown in the fig. 2. At the end of the $6^{\text {th }} \mathrm{h} \mathrm{F}_{1}$ showed highest drug release of $97.78 \%$ and $\mathrm{F}_{6}$ is $86.17 \%$. In case of HPMC E5 formulations, at the end of the $6^{\text {th }} \mathrm{h}$ F7 showed highest drug release of $94.5 \%$ and $\mathrm{F} 12$ is $86.47 \%$. The significant decrease in drug release is found as the polymer concentration increases in formulations from F1 to F6. Meher et al [2] states that this could be related to the increase in thickness of the film with an increase in HPMC concentration. Thus the time requires for dissolution medium to penetrate into the polymer chain located through the depth of the film increases.

Similar observation is made with HPMC E5 formulations also. However initial drug release ( $30 \mathrm{~min})$ is more as compared to other formulations. This might be because of low viscosity of HPMC E5 polymer as observed by Magdy et al., [12]

At the end of the $6^{\text {th }} \mathrm{h}$ F13 showed highest drug release of $76.44 \%$ and F18 is $68.73 \%$. In the case of chitosan containing formulations drug release values after completion of $6^{\text {th }} \mathrm{h}$ is lower as compared to other formulations. Similar observation is found by author Patel R P et al., [1] chitosan is a cationic polymer which might have formed complex with PVP K30 (polymer used to prepare solid dispersions which is incorporated in the transbuccal films), which is non-ionic polymer leading to extension of the drug release.
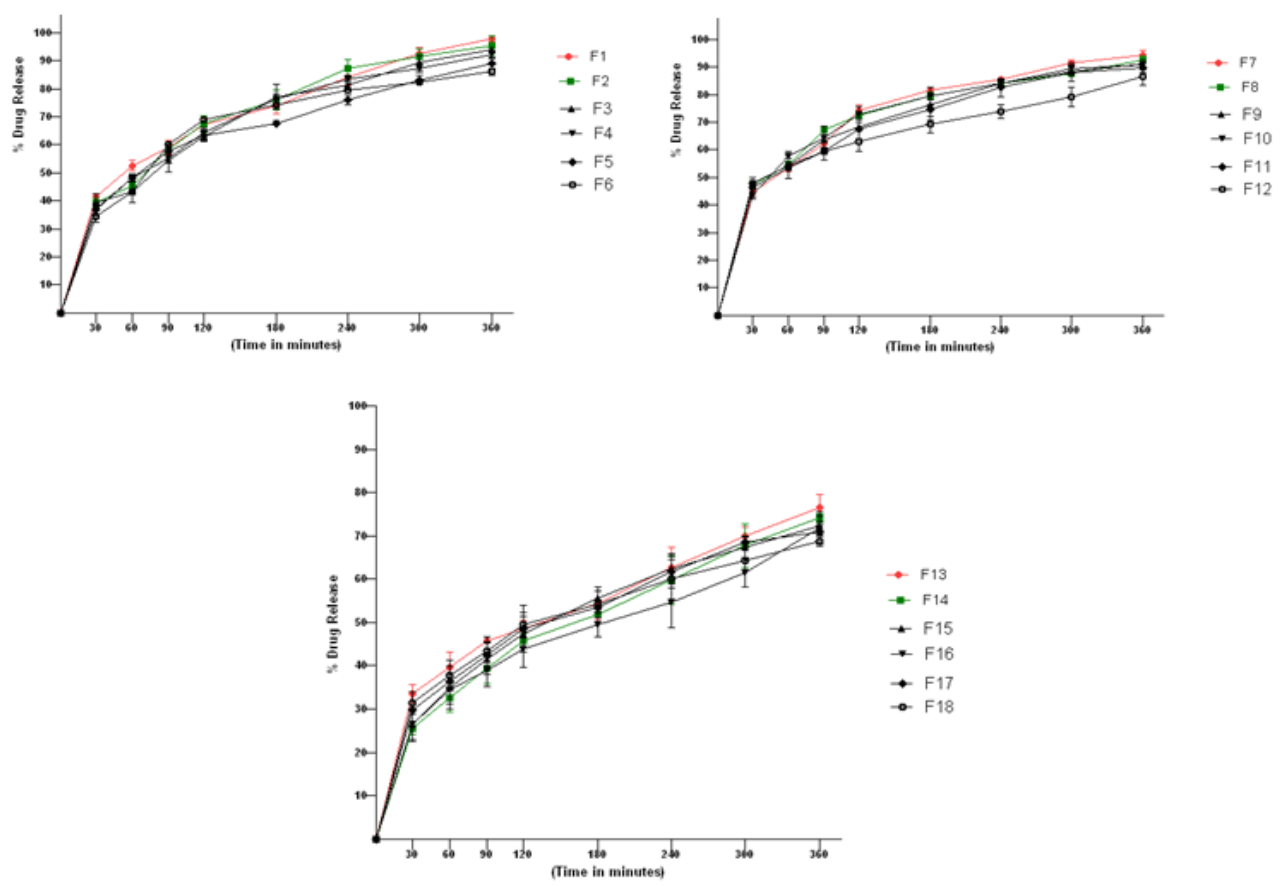

Fig. 2: Percentage drug release profile of transbuccal films (F1-F18) (Values are expressed as mean \pm SD, n=3)


Fig. 3: Percentage drug permeation profile of transbuccal films (F1-F18) (Values are expressed as mean \pm SD, $n=3$ ) 


\section{Ex-vivo drug permeation study}

The fig. 3 shows the drug permeation profile of formulations. Drug permeated at the $6^{\text {th }} \mathrm{h}$ of $\mathrm{F}_{1}$ is $96.78 \%$ and $\mathrm{F} 6$ is $68.42 \%$. Similarly, F7 is $90.45 \%$ and $\mathrm{F} 1271.56 \%$. In case of HPMC polymers, formation of hydrogel occurs at the surface of biomembrane, which leads to hydration and swelling of mucoadhesive films which promotes diffusion of drug Drug permeated at the end of the $6^{\text {th }} \mathrm{h}$ of F13 is $73.25 \%$ and F18 is 57.34 $\%$. As discussed in the study of swelling index, chitosan films when wetted can gain weight and size by $150 \%$ due to swelling of mucoadhesive films, formation of very thick hydrogen layer leads to the longer diffusion path length leading into delayed diffusion. Castan et al. [4] states that drug diffusion is delayed in the case of ionic polymers such as chitosan as compared to nonionic polymers (HPMC).

To investigate the release kinetics of drug release from buccal films, the in vitro drug release and ex-vivo permeation data were subjected to fit various kinetic models using PCP Disso ver 2 software Pune India. The $\mathbf{r}^{2}$ and $\mathbf{n}$ values are determined. All the buccal films showed $n$ values in the range of 0.73 to 0.87 , indicating that the drug release followed by nonfickian diffusion and the best fit model observed to be higuchi model.

Based on results of Drug content, swelling index, folding endurance in vitro bioadhesion, in vitro drug release and ex-vivo permeation, we can conclude that HPMCK4M formulations (F1-F6) are best formulations. The formulation F3 is selected for the further stability study.

\section{Stability study}

Accelerated stability data is given in table 10 . The results of the stability study revealed that there is no significant change in drug content, in vitro drug release and ex-vivo permeation.

Table 10: Accelerated stability data of the best formulation F3

\begin{tabular}{llll}
\hline Time & Drug content & \% drug released $^{*}$ & \% drug permeated $^{*}$ \\
\hline Initial & $93.80 \pm 0.71$ & $93.13 \pm 2.15$ & $92.34 \pm 1.14$ \\
1 mo & $93.21 \pm 0.37$ & $92.17 \pm 3.17$ & $92.23 \pm 1.67$ \\
2 mo & $92.34 \pm 0.54$ & $92.45 \pm 1.13$ & $91.45 \pm 2.44$ \\
3 mo & $91.46 \pm 0.56$ & $91.17 \pm 2.23$ & $91.87 \pm 1.24$ \\
\hline
\end{tabular}

* Data are expressed as mean \pm standard deviation of the mean [SD], $n=3$.

\section{CONCLUSION}

Mucoadhesive films of spraydried LVS were successfully developed by using 3 different polymers HPMCK4M, HPMCE5LV and chitosan. An in vitro charecterisation result shows that HPMCK4M formulations are best formulations. Drug release and permeation were found to be nonfickian diffusion and best fit model observed to be higuchi model. Stability study data revealed that there is no significant change in the drug content, in vitro drug release and $e x$ vivo permeation. By using transbuccal mucoadhesive films, it can enhance the drug bioavailability by preventing the first-pass metabolism thus providing better therapeutic efficacy.

\section{AUTHORS CONTRIBUTIONS}

All the author have contributed equally

\section{CONFLICT OF INTERESTS}

Declared none

\section{REFERENCES}

1. Pankaj Kumar, Gulshan Chhabra, Kamla Pathak. Development and statistical optimization of bioadhesive films of Amiloride hydrochloride: in vitro and ex-vivo evaluation. Ind J Pharm Edu Res 2012;46:145-54.

2. Meher JG, Tarai M, Yadav NP, Pathak A, Mishra P, Yadav K. Development and characterization of cellulosepolymethacrylate mucoadhesive film for buccal delivery of carvedilol. Carbohydr Polym 2017;96:172-80.

3. K Chandra Sekhar, KVS Naidu, Y Vamshi Vishnu, Ramesh Gannu, V Kishan, Y Madhusudan Rao. Transbuccal delivery of chlorpheniramine maleate from mucoadhesive buccal patches. Drug Delivery 2008;15:185-91.

4. Castan H, Ruiz B, Morales M, Design. Development and characterisation of buccal bioadhesive films of doxepin for treatment of odontalgia. Drug Delivery 2017;22:869-76.

5. Tripathi KD. Essentials of medical pharmacology. $6^{\text {th }}$ ed. Jaypee brothers medical publishers; 2010.

6. Patel RP, Patel MM. Physicochemical charecterization and dissolution study of solid dispersions of lovastatin with PEG 4000 and Polyvinylpyrrolidone K30. Pharm Dev Technol 2007;12:21-33.

7. Parfitt K. Lipid regulating drugs: lovastatin, Martindale. $32^{\text {nd }}$ ed. The Pharmaceutical Press; 1999.

8. Gerald SB, KE Micheal, JK Lovastatin. Analytical profiles of drug substances and excipients. $1^{\text {st }}$ ed. Acadaemic Press; 1998.

9. Jagadale S, Hable A, Kuchekar B. Improvement of dissolution rate of chlorzoxazone by solid dispersion technique and development of buccal patch. J Appl Sol Chem Model 2013;2:145-57.

10. Hassan MA, Barakat NS, El-Badry M, Shehata SM. Formulation and in vitro and in vivo evaluation of naproxen mucoadhesive buccal patches for local effect. J Drug Delivery Sci Technol 2011;21:423-31.

11. Patel RP, Poddar SS. Deveopment and characterization of mucoadhesive buccal patches of salbutamol sulphate. Curr Drug Delivery 2009;6:140-4.

12. Magdy M, Nadia S, Sarah R. Development of a novel ketorolac tromethamine sublingual film. J Am Sci 2015;11:27-37.

13. Cui F, Chunbai H, Miao H, Cui Tang, Lichen Y, Feng Q. Preperation and evaluation of chitosan-ethylenediaminetetraacetic acid hydrogel films for the mucoadhesive transbuccal delivery of insulin. J Biomed Mater Res 2008;89:1063-71. 